\title{
Collective and Tracer Diffusion Kinetics in the Ternary Random Alloy
}

\author{
I.V. Belova", A.R. Allnatt and G.E. Murch" \\ Department of Chemistry, University of Western Ontario \\ London, Ontario N6A 5B7, CANADA \\ IDiffusion in Solids Group, Department of Mechanical Engineering \\ University of Newcastle, Callaghan, NSW 2308, AUSTRALIA
}

\begin{abstract}
In this study, collective and tracer diffusion kinetics are addressed for the ternary random alloy. A formal solution from the self-consistent theory of Moleko et al. (1989) is derived for collective diffusion and compared with the corresponding solution for the binary random alloy. Tracer diffusion in the ternary alloy is treated from the perspective of a special case of the quaternary random alloy. Results from Monte Carlo calculations for tracer and collective correlation factors (for the bcc ternary random alloy) are found to be in excellent agreement with this self-consistent theory but in only semi-quantitative agreement with the earlier theory of Manning (1971).
\end{abstract}

\section{§ 1. Introduction}

The random alloy model has long been useful for describing diffusion kinetics in concentrated disordered alloys. Introduced first by Manning $(1968,1971)$ the random alloy model requires that both the atomic components and the defect responsible for diffusion are randomly mixed. Taking diffusion by vacancies in the ternary random alloy as a specific example, the randomly mixed atomic components $\mathrm{X}_{1}, \mathrm{X}_{2}, \mathrm{X}_{3}$ exchange with the vacancies at frequencies $\mathrm{w}_{1}, \mathrm{w}_{2}$ and $\mathrm{w}_{3}$ respectively and the vacancies are present at a vanishingly small concentration. Manning $(1968,1971)$ derived simple expressions for the tracer correlation factors in terms of the exchange frequencies. Related expressions were also developed for the tracer correlation factors in terms of the tracer diffusivities themselves. These latter expressions are a valuable alternative to obtaining the tracer correlation factors via analysis of the isotope effect.

Early Monte Carlo calculations in the binary random alloy implied that the Manning formalism for describing the tracer correlation factors was remarkably accurate over a wide range of exchange frequency ratios. But recent high precision Monte Carlo work (Belova and Murch, 2000a) has made it clear that much of this success was in fact illusory, coming as a result of specifying vacancy jump sequences that were much too short. There was in fact much better agreement with the results of the formalism of Holdsworth and Elliott (1986) (hereon abbreviated to HE). That formalism used a method of decoupling a hierarchy of equations of motion. However, almost exact agreement over a very wide range of the ratios of exchange frequencies was obtained with the results from a self-consistent theory of Moleko et al. (1989) (hereon abbreviated by MAA). This theory makes use of a hierarchy of kinetic equations for the time-dependent correlation functions from linear response theory. The decoupling 
approximation used by MAA is similar in spirit to that used by HE but is adapted to the different hierarchy of equations in the MAA theory.

The correlated parts of the Onsager phenomenological coefficients associated with atom components present in more than tracer amounts are often called collective correlation factors. Manning $(1968,1971)$ derived expressions for the collective correlation factors of a random alloy with an arbitrary number of atom components, but $\mathrm{HE}$ did not extend their formalism to address this problem. Equations determining the collective correlation factors for a random alloy with an arbitrary number of components were obtained with the MAA self-consistent theory but an explicit solution was given only for a binary alloy. The latter turned out to be equivalent to that obtained by Manning for this system (Belova and Murch 2000b). Recent results from high precision Monte Carlo calculations for the binary random alloy are in excellent agreement with these expressions over a very wide range of the ratios of the exchange frequencies (Belova and Murch 2000b).

As a result of the findings summarized above and related ones addressing the vacancy wind effect (Belova and Murch 2001) and the isotope effect (Belova and Murch 2000c) it can be safely said that diffusion kinetics in the binary random alloy are very accurately described by MAA. This is no guarantee of course that similar success of this theory can be expected for alloys of more than two atomic components. In the present paper we address the collective and tracer correlation factors in the ternary random alloy. In Section 2 we derive specific expressions for the ternary collective and tracer correlation factors based on the general equation (Eqn 48) presented in MAA. In Section 3 we describe high precision Monte Carlo calculations of the collective and tracer correlation factors. This is followed in Section 4 by a presentation and comparison of the results.

\section{$\S 2$. Theory.}

\section{Collective Correlation Factors.}

First we consider the ternary system: $\left(\mathrm{X}_{1}, \mathrm{X}_{2}, \mathrm{X}_{3}\right)$ with atom-vacancy exchange frequencies $\mathrm{w}_{1}, \mathrm{w}_{2}$ and $\mathrm{w}_{3}$, atomic compositions $\mathrm{c}_{1}, \mathrm{c}_{2}, \mathrm{c}_{3}$ and a vacancy site fraction $\mathrm{C}_{\mathrm{V}}$ which is vanishingly small.

We follow the same notation introduced in MAA, where the collective correlation factors $\mathrm{f}_{\mathrm{ij}}(\mathrm{j})$ are expressed as

$$
\mathrm{f}_{\mathrm{ij}}^{(\mathrm{j})}=\delta_{\mathrm{ij}}-2 \mathrm{w}_{\mathrm{i}} \mathrm{U}\left(\mathrm{VX}_{\mathrm{i}}: \mathrm{VX}_{\mathrm{j}}\right)\left(\mathrm{c}_{\mathrm{v}} \mathrm{c}_{\mathrm{j}}\right)^{-1}
$$

where $\delta_{\mathrm{ij}}$ is the Krönecker delta. The $\mathrm{U}$ functions obey relations which ensure that the correlation functions are consistent with the Onsager reciprocal relations and with the sum rule for the random alloy (Moleko and Allnatt 1988). These relations are $\mathrm{U}\left(\mathrm{VX}_{\mathrm{I}}: \mathrm{VX}_{\mathrm{j}}\right)=\mathrm{U}\left(\mathrm{VX}_{\mathrm{j}}: \mathrm{VX}_{\mathrm{I}}\right)$ and

$$
\mathrm{U}\left(\mathrm{VX}_{1}: \mathrm{VX}_{\mathrm{j}}\right)+\mathrm{U}\left(\mathrm{VX}_{2}: \mathrm{VX}_{\mathrm{j}}\right)+\mathrm{U}\left(\mathrm{VX}_{3}: \mathrm{VX}_{\mathrm{j}}\right)=0
$$

It follows that there are only three independent functions. We therefore introduce

$$
\mathrm{g}_{1}=\mathrm{U}\left(\mathrm{VX}_{1}: \mathrm{VX}_{2}\right)\left(=\mathrm{U}\left(\mathrm{VX}_{2}: \mathrm{VX}_{1}\right)\right), \mathrm{g}_{2}=\mathrm{U}\left(\mathrm{VX}_{1}: \mathrm{VX}_{3}\right)\left(=\mathrm{U}\left(\mathrm{VX}_{3}: \mathrm{VX}_{1}\right)\right) \text {, }
$$




$$
\mathrm{g}_{3}=\mathrm{U}\left(\mathrm{VX}_{2}: \mathrm{VX}_{3}\right)\left(=\mathrm{U}\left(\mathrm{VX}_{3}: \mathrm{VX}_{2}\right)\right) \text {. }
$$

For the ternary random alloy Eqn 1 then will take the forms

$$
\begin{gathered}
\mathrm{f}_{11}=1+2 \mathrm{w}_{1}\left(\mathrm{~g}_{1}+\mathrm{g}_{2}\right)\left(\mathrm{c}_{\mathrm{v}} \mathrm{c}_{1}\right)^{-1} ; \mathrm{f}_{22}=1+2 \mathrm{w}_{2}\left(\mathrm{~g}_{1}+\mathrm{g}_{3}\right)\left(\mathrm{c}_{\mathrm{v}} \mathrm{c}_{2}\right)^{-1} ; \mathrm{f}_{33}=1+2 \mathrm{w}_{3}\left(\mathrm{~g}_{2}+\mathrm{g}_{3}\right)\left(\mathrm{c}_{\mathrm{v}} \mathrm{c}_{3}\right)^{-1} ; \\
\mathrm{f}_{12}{ }^{(1)}=-2 \mathrm{w}_{2} \mathrm{~g}_{1}\left(\mathrm{c}_{\mathrm{v}} \mathrm{c}_{1}\right)^{-1} ; \mathrm{f}_{13}{ }^{(1)}=-2 \mathrm{w}_{3} \mathrm{~g}_{2}\left(\mathrm{c}_{\mathrm{v}} \mathrm{c}_{1}\right)^{-1} ; \mathrm{f}_{23}{ }^{(2)}=-2 \mathrm{w}_{3} \mathrm{~g}_{3}\left(\mathrm{c}_{\mathrm{v}} \mathrm{C}_{2}\right)^{-1} ; \\
\mathrm{f}_{12}{ }^{(2)}=\mathrm{c}_{1} \mathrm{w}_{1} \mathrm{f}_{12}{ }^{(1)}\left(\mathrm{c}_{2} \mathrm{w}_{2}\right)^{-1} ; \mathrm{f}_{13}{ }^{(3)}=\mathrm{c}_{1} \mathrm{w}_{1} \mathrm{f}_{13}{ }^{(1)}\left(\mathrm{c}_{3} \mathrm{w}_{3}\right)^{-1} ; \mathrm{f}_{23}{ }^{(3)}=\mathrm{c}_{2} \mathrm{w}_{2} \mathrm{f}_{23}{ }^{(2)}\left(\mathrm{c}_{3} \mathrm{w}_{3}\right)^{-1}
\end{gathered}
$$

We assume that, in accord with all previous calculations for simple vacancy transport models, the phenomenological coefficients $\mathrm{L}_{\mathrm{ij}}$ are all $\mathrm{O}\left(\mathrm{c}_{\mathrm{v}}\right)$; we then find that all

$$
\left(g_{1}, g_{2}, g_{3}\right)=O\left(c_{v}\right)
$$

The general equation in MAA contains additional functions which have a skew symmetry property, $\mathrm{U}\left(\mathrm{X}_{\mathrm{i}} \mathrm{X}_{\mathrm{j}}: \mathrm{VX}_{\mathrm{k}}\right)=-\mathrm{U}\left(\mathrm{X}_{\mathrm{j}} \mathrm{X}_{\mathrm{i}}: \mathrm{VX}_{\mathrm{k}}\right)$, and are related to the earlier functions by

$$
\mathrm{U}\left(\mathrm{VX}_{\mathrm{i}}: \mathrm{VX}_{\mathrm{j}}\right)=-\mathrm{U}\left(\mathrm{X}_{1} \mathrm{X}_{\mathrm{i}}: \mathrm{VX}_{\mathrm{j}}\right)-\mathrm{U}\left(\mathrm{X}_{2} \mathrm{X}_{\mathrm{i}}: \mathrm{VX}_{\mathrm{j}}\right)-\mathrm{U}\left(\mathrm{X}_{3} \mathrm{X}_{\mathrm{i}}: \mathrm{VX}\right)
$$

We introduce

$$
\mathrm{y}_{1}=\mathrm{U}\left(\mathrm{X}_{1} \mathrm{X}_{2}: \mathrm{VX}_{1}\right), \quad \mathrm{y}_{2}=\mathrm{U}\left(\mathrm{X}_{1} \mathrm{X}_{2}: \mathrm{VX}_{2}\right), \mathrm{y}_{3}=\mathrm{U}\left(\mathrm{X}_{1} \mathrm{X}_{2}: \mathrm{VX}_{3}\right) .
$$

It follows from Eqns 5 and 6 that

$$
\mathrm{U}\left(\mathrm{VX}_{1}: \mathrm{VX}_{1}\right)=\mathrm{y}_{1}-\mathrm{U}\left(\mathrm{X}_{3} \mathrm{X}_{1}: \mathrm{VX}_{1}\right)=\mathrm{O}\left(\mathrm{c}_{\mathrm{v}}\right)
$$

Consistent with this result, we accept the approximation $\mathrm{U}\left(\mathrm{X}_{3} \mathrm{X}_{1}: \mathrm{VX}_{1}\right) \approx \mathrm{y}_{1}$, with both functions independent of $c_{v}$. By means of analogous approximations for other functions of this type we find

$$
\mathrm{y}_{\mathrm{k}}=\mathrm{U}\left(\mathrm{X}_{1} \mathrm{X}_{2}: \mathrm{VX}_{\mathrm{k}}\right)=\mathrm{U}\left(\mathrm{X}_{2} \mathrm{X}_{3}: \mathrm{VX}_{\mathrm{k}}\right)=\mathrm{U}\left(\mathrm{X}_{3} \mathrm{X}_{1}: \mathrm{VX}_{\mathrm{k}}\right) \quad \text { for } \mathrm{k}=1,2,3
$$

With these approximations and definitions in hand we can write down a set of five equations for five unknown variables which can be chosen from the six $\left(g_{1}, g_{2}, g_{3} ; y_{1}\right.$, $\left.\mathrm{y}_{2}, \mathrm{y}_{3}\right)$ in three ways with respect to the choice of the first jump. (For $\mathrm{U}\left(\mathrm{VX}_{\mathrm{i}}: \mathrm{VX}_{\mathrm{k}}\right.$ ) and $\mathrm{U}\left(\mathrm{X}_{\mathrm{i}} \mathrm{X}_{\mathrm{j}}: \mathrm{VX}_{\mathrm{k}}\right)$ the first jump is $\mathrm{VX}_{\mathrm{k}}$. Note also that in each MAA equation all the functions have the same first jump.) We can have ( $\left.g_{1}, g_{2}, g_{3} ; y_{1}, y_{2}\right)$ as unknown variables (three equations for the first jump $\mathrm{VX}_{1}$ and two equations for the first jump $\left.\mathrm{VX}_{2}\right)$ :

$\mathrm{M}_{0} \mathrm{c}_{\mathrm{v}} \mathrm{y}_{1}\left(\mathrm{~g}-\mathrm{w}_{3} \mathrm{~F}_{3}\right)=\mathrm{c}_{1} \mathrm{c}_{2} \mathrm{c}_{\mathrm{v}}+\mathrm{c}_{2}\left(\mathrm{~g}_{1}+\mathrm{g}_{2}\right)\left(2 \mathrm{w}_{1}+\mathrm{M}_{0} \mathrm{w}_{2} \mathrm{~F}_{2}\right)+\mathrm{c}_{1} \mathrm{~g}_{1}\left(2 \mathrm{w}_{2}+\mathrm{M}_{0} \mathrm{w}_{1} \mathrm{~F}_{1}\right) ;$

$\mathrm{M}_{0} \mathrm{c}_{\mathrm{v}} \mathrm{y}_{1}\left(\mathrm{~g}-\mathrm{w}_{1} \mathrm{~F}_{1}\right)=-\mathrm{c}_{3} \mathrm{~g}_{1}\left(2 \mathrm{w}_{2}+\mathrm{M}_{0} \mathrm{w}_{3} \mathrm{~F}_{3}\right)+\mathrm{c}_{2} \mathrm{~g}_{2}\left(2 \mathrm{w}_{3}+\mathrm{M}_{0} \mathrm{w}_{2} \mathrm{~F}_{2}\right) ;$

$\mathrm{M}_{0} \mathrm{c}_{\mathrm{v}} \mathrm{y}_{1}\left(-g+\mathrm{w}_{2} \mathrm{~F}_{2}\right)=\mathrm{c}_{1} \mathrm{c}_{3} \mathrm{c}_{\mathrm{v}}+\mathrm{c}_{3}\left(\mathrm{~g}_{1}+\mathrm{g}_{2}\right)\left(2 \mathrm{w}_{1}+\mathrm{M}_{0} \mathrm{w}_{3} \mathrm{~F}_{3}\right)+\mathrm{c}_{1} \mathrm{~g}_{2}\left(2 \mathrm{w}_{3}+\mathrm{M}_{0} \mathrm{w}_{1} \mathrm{~F}_{1}\right) ;$ 
$\mathrm{M}_{0} \mathrm{c}_{\mathrm{v}} \mathrm{y}_{2}\left(-g+\mathrm{w}_{3} \mathrm{~F}_{3}\right)=\mathrm{c}_{1} \mathrm{c}_{2} \mathrm{c}_{\mathrm{v}}+\mathrm{c}_{2} \mathrm{~g}_{1}\left(2 \mathrm{w}_{1}+\mathrm{M}_{0} \mathrm{w}_{2} \mathrm{~F}_{2}\right)+\mathrm{c}_{1}\left(\mathrm{~g}_{1}+\mathrm{g}_{3}\right)\left(2 \mathrm{w}_{2}+\mathrm{M}_{0} \mathrm{w}_{1} \mathrm{~F}_{1}\right) ;$

$M_{0} c_{v} y_{2}\left(-g+w_{2} F_{2}\right)=-c_{3} g_{1}\left(2 w_{1}+M_{0} w_{3} F_{3}\right)+c_{1} g_{3}\left(2 w_{3}+M_{0} w_{1} F_{1}\right)$.

In the above equations we have used the following notation:

$$
\begin{gathered}
g=w_{1} f_{11}+w_{2} f_{22}+w_{3} f_{33} ; F_{1}=f_{11}+f_{12}{ }^{(1)}+f_{13}{ }^{(1)} ; F_{2}=f_{22}+f_{12}{ }^{(2)}+f_{23}{ }^{(2)} ; \\
F_{3}=f_{33}+f_{13}{ }^{(3)}+f_{23}{ }^{(3)} ; M_{0}=2 f_{0}\left(1-f_{0}\right)^{-1}
\end{gathered}
$$

where $\mathrm{f}_{0}$ is the geometric tracer correlation factor, which takes different values for different crystal structures (and mechanisms) see, for example, the classic review by Le Claire (1970). This system of equations (Eqns 10-14) is a restatement for the ternary random alloy of the general Eqn 48 in MAA.

The functions $g, F_{1}, F_{2}, F_{3}$ can all be expressed in terms of $g_{1}, g_{2}$ and $g_{3}$ as follows:

$$
\begin{array}{cc}
g= & w_{1}+w_{2}+w_{3}+2\left(w_{1}^{2}\left(g_{1}+g_{2}\right)\left(c_{v} c_{1}\right)^{-1}+w_{2}^{2}\left(g_{1}+g_{3}\right)\left(c_{v} c_{3}\right)^{-1}+w_{3}^{2}\left(g_{2}+g_{3}\right)\left(c_{v} c_{3}\right)^{-1}\right) ; \\
F_{1}=1+2\left(g_{1}\left(w_{1}-w_{2}\right)+g_{2}\left(w_{1}-w_{3}\right)\right)\left(c_{v} c_{1}\right)^{-1} \\
F_{2}=1+2\left(g_{1}\left(w_{2}-w_{1}\right)+g_{3}\left(w_{2}-w_{3}\right)\right)\left(c_{v} c_{2}\right)^{-1} \\
F_{3}=1+2\left(g_{2}\left(w_{3}-w_{1}\right)+g_{3}\left(w_{3}-w_{2}\right)\right)\left(c_{v} c_{3}\right)^{-1} .
\end{array}
$$

It was shown in Murch and Qin (1994) that $F_{1}$ has the meaning of the partial vacancy correlation factor $f_{v}{ }^{1}$ (Manning 1968), similarly $F_{2}$ and $F_{3}$ correspond to $f_{v}{ }^{2}$ and $f_{v}{ }^{3}$ respectively.

We can see that in general the system of equations (Eqns 10 - 14) is essentially nonlinear. We can treat the system as a linear one with the coefficients playing the role of parameters. Then we can derive the following very formal solution:

$$
\begin{aligned}
& g_{1}=-c_{1} c_{2} c_{3} c_{v}(g-G) A(A B+A C+B C)^{-1} ; \\
& g_{2}=-c_{1} c_{2} c_{3} c_{v}(g-G) B(A B+A C+B C)^{-1} ; \\
& g_{3}=-c_{1} c_{2} c_{3} c_{v}(g-G) C(A B+A C+B C)^{-1},
\end{aligned}
$$

where

$$
\begin{gathered}
G=c_{1} w_{1} F_{1}+c_{2} w_{2} F_{2}+c_{3} w_{3} F_{3} ; \\
A=M_{0}\left(c_{1} G-c_{1} w_{1} F_{1}\right)\left(c_{2} G-c_{2} w_{2} F_{2}\right)+c_{1} c_{2}(g-G)\left(M_{0} G+2 w_{3}\right) ; \\
B=M_{0}\left(c_{1} G-c_{1} w_{1} F_{1}\right)\left(c_{3} G-c_{3} w_{3} F_{3}\right)+c_{1} c_{3}(g-G)\left(M_{0} G+2 w_{2}\right) ;
\end{gathered}
$$




$$
\mathrm{C}=\mathrm{M}_{0}\left(\mathrm{c}_{2} \mathrm{G}-\mathrm{C}_{2} \mathrm{w}_{2} \mathrm{~F}_{2}\right)\left(\mathrm{c}_{3} \mathrm{G}-\mathrm{C}_{3} \mathrm{w}_{3} \mathrm{~F}_{3}\right)+\mathrm{C}_{2} \mathrm{C}_{3}(\mathrm{~g}-\mathrm{G})\left(\mathrm{M}_{0} \mathrm{G}+2 \mathrm{w}_{1}\right) .
$$

The relations (Eqns 19 - 21) should be compared with the corresponding solution in the case of the binary random alloy:

$$
g_{1}=-c_{1} C_{2} C_{v}\left(M_{0} G+2\left(w_{1} C_{2}+w_{2} C_{1}\right)\right)^{-1},
$$

which can be derived as a limit of the first relation (Eqn 19) when $\mathrm{C}_{3} \rightarrow 0$. In this limit $\mathrm{A}=\mathrm{O}\left(\mathrm{c}_{\mathrm{v}}\right), \mathrm{B}=\mathrm{O}\left(\mathrm{c}_{3} \mathrm{c}_{\mathrm{v}}\right), \mathrm{C}=\mathrm{O}\left(\mathrm{c}_{3} \mathrm{c}_{\mathrm{v}}\right)$. Then we have for $\mathrm{g}_{1}$ :

$$
g_{1}=\lim _{c_{3} \rightarrow 0}-c_{1} c_{2} c_{v} c_{3}(g-G)(B+C)^{-1},
$$

from Eqns 24, 25 we have that

$$
\begin{aligned}
& \lim _{c_{3} \rightarrow 0}(B+C) c_{3}^{-1}=\lim _{c_{3} \rightarrow 0}\left(\left(\left(c_{1}+c_{2}\right) G-c_{1} w_{1} F_{1}-c_{2} w_{2} F_{2}\right)\left(G-w_{3} F_{3}\right)\right) \\
& +(g-G)\left(M_{0} G+2\left(w_{1} c_{2}+w_{2} c_{1}\right)\right)=0+(g-G)\left(M_{0} G+2\left(w_{1} c_{2}+w_{2} c_{1}\right)\right)
\end{aligned}
$$

which together with Eqn 27 gives the final expression Eqn 26.

In the case of the binary random alloy it was possible to use this solution directly for numerical calculations (Belova and Murch 2000b). Unfortunately, for the ternary random alloy, in general, the amount of calculation required by making use of the formal solution Eqns 19 - 21 is approximately equal to that by making use of the original system of equations (Eqns $10-14$ ). This is because despite the clear structure of the solution Eqns 19 - 21 it still involves the five unknown functions: A, B, C, g and $\mathrm{G}$.

Manning's (1971) solution for the collective correlation factors for the ternary random alloy is as follows:

$$
\begin{aligned}
& \mathrm{g}_{1}^{\mathrm{M}}=-\mathrm{c}_{\mathrm{v}} \mathrm{c}_{1} \mathrm{c}_{2}\left(\mathrm{H}+2 \mathrm{w}_{3}\right) \times \\
& \left(\mathrm{c}_{1}\left(\mathrm{H}+2 \mathrm{w}_{2}\right)\left(\mathrm{H}+2 \mathrm{w}_{3}\right)+\mathrm{c}_{2}\left(\mathrm{H}+2 \mathrm{w}_{1}\right)\left(\mathrm{H}+2 \mathrm{w}_{3}\right)+\mathrm{c}_{3}\left(\mathrm{H}+2 \mathrm{w}_{1}\right)\left(\mathrm{H}+2 \mathrm{w}_{2}\right)\right)^{-1} \\
& \mathrm{~g}_{2}^{\mathrm{M}}=-\mathrm{c}_{\mathrm{v}} \mathrm{c}_{1} \mathrm{c}_{3}\left(\mathrm{H}+2 \mathrm{w}_{2}\right) \times \\
& \left(\mathrm{c}_{1}\left(\mathrm{H}+2 \mathrm{w}_{2}\right)\left(\mathrm{H}+2 \mathrm{w}_{3}\right)+\mathrm{c}_{2}\left(\mathrm{H}+2 \mathrm{w}_{1}\right)\left(\mathrm{H}+2 \mathrm{w}_{3}\right)+\mathrm{c}_{3}\left(\mathrm{H}+2 \mathrm{w}_{1}\right)\left(\mathrm{H}+2 \mathrm{w}_{2}\right)\right)^{-1} \\
& \mathrm{~g}_{3}^{\mathrm{M}}=-\mathrm{c}_{\mathrm{v}} \mathrm{c}_{2} \mathrm{c}_{3}\left(\mathrm{H}+2 \mathrm{w}_{1}\right) \times \\
& \left(\mathrm{c}_{1}\left(\mathrm{H}+2 \mathrm{w}_{2}\right)\left(\mathrm{H}+2 \mathrm{w}_{3}\right)+\mathrm{c}_{2}\left(\mathrm{H}+2 \mathrm{w}_{1}\right)\left(\mathrm{H}+2 \mathrm{w}_{3}\right)+\mathrm{c}_{3}\left(\mathrm{H}+2 \mathrm{w}_{1}\right)\left(\mathrm{H}+2 \mathrm{w}_{2}\right)\right)^{-1}
\end{aligned}
$$

where $\mathrm{H}$ is a positive real solution to the equation: 


$$
\begin{gathered}
\left(\mathrm{M}_{0}+2\right)\left(\mathrm{c}_{1} \mathrm{w}_{1}\left(\mathrm{H}+2 \mathrm{w}_{2}\right)\left(\mathrm{H}+2 \mathrm{w}_{3}\right)+\mathrm{c}_{2} \mathrm{w}_{2}\left(\mathrm{H}+2 \mathrm{w}_{1}\right)\left(\mathrm{H}+2 \mathrm{w}_{3}\right)+\mathrm{c}_{3} \mathrm{w}_{3}\left(\mathrm{H}+2 \mathrm{w}_{1}\right)\left(\mathrm{H}+2 \mathrm{w}_{2}\right)\right) \\
=\left(\mathrm{H}+2 \mathrm{w}_{1}\right)\left(\mathrm{H}+2 \mathrm{w}_{2}\right)\left(\mathrm{H}+2 \mathrm{w}_{3}\right) .
\end{gathered}
$$

As a point of interest, if we neglect the first terms of the functions $A, B$ and $C$ (Eqns 23-25) and use the relation $\mathrm{H}=\mathrm{M}_{0} \mathrm{G}$, then it is possible to show that the MAA Eqns 19-21 reduce to Manning's solution Eqns 29 - 32.

\section{Tracer Correlation Factors.}

In order to address the tracer correlation factors for the ternary random alloy in the MAA formalism we need to consider the quaternary random alloy system $\left(X_{1}, X_{2}, X_{3}\right.$, $\mathrm{X}_{4}$ ) with atom-vacancy exchange frequencies $\mathrm{w}_{1}, \mathrm{w}_{2}, \mathrm{w}_{3}$ and $\mathrm{w}_{4}$ and atomic compositions $c_{1}, c_{2}, c_{3}$ and $c_{4}$ and vanishingly small $c_{v}$. Then we can use the following expression for the tracer correlation factor $\mathrm{f}_{1}$ (and a similar method can be used in order to find $\mathrm{f}_{2}$ and $\mathrm{f}_{3}$ ):

$$
\mathrm{f}_{\mathrm{i}}=\lim _{\mathrm{c}_{4} \rightarrow 0} \mathrm{f}_{44},
$$

where the subscript $i$ denotes the type of tracer atoms $\left(X_{1}, X_{2}\right.$ or $\left.X_{3}\right)$. We consider only the situation after the first jump $v-X_{4}$. Let us introduce $h_{1}, h_{2}, h_{3}$ functions in a way similar to that for the $\mathrm{g}_{1}, \mathrm{~g}_{2}$ and $\mathrm{g}_{3}$ functions (Eqns 3):

$$
\mathrm{h}_{1}=\mathrm{U}\left(\mathrm{VX}_{1}: \mathrm{VX}_{4}\right), \quad \mathrm{h}_{2}=\mathrm{U}\left(\mathrm{VX}_{2}: \mathrm{VX}_{4}\right), \quad \mathrm{h}_{3}=\mathrm{U}\left(\mathrm{VX}_{3}: \mathrm{VX}_{4}\right) .
$$

Now, we have that

$$
\mathrm{h}=\mathrm{U}\left(\mathrm{VX}_{4}: \mathrm{VX}_{4}\right)=-\mathrm{h}_{1}-\mathrm{h}_{2}-\mathrm{h}_{3},
$$

together with

$$
\mathrm{f}_{44}=1-2 \mathrm{w}_{4} \mathrm{~h}\left(\mathrm{c}_{\mathrm{v}} \mathrm{C}_{4}\right)^{-1} \text {. }
$$

We will need additional functions of the type $\mathrm{y}_{\mathrm{i}}$ (of Eqns 7 type):

$$
\mathrm{y}_{4}=\mathrm{U}\left(\mathrm{X}_{2} \mathrm{X}_{1}: \mathrm{VX}_{4}\right), \quad \mathrm{y}_{5}=\mathrm{U}\left(\mathrm{X}_{3} \mathrm{X}_{1}: \mathrm{VX}_{4}\right), \quad \mathrm{y}_{6}=\mathrm{U}\left(\mathrm{X}_{3} \mathrm{X}_{2}: \mathrm{VX}_{4}\right) \text {. }
$$

Then, after making use of an asymptotical consideration with respect to the small quantity $\mathrm{C}_{\mathrm{v}}$ (similar to that for the ternary random alloy case), we have that

$$
\mathrm{U}\left(\mathrm{X}_{1} \mathrm{X}_{4}: \mathrm{VX}_{4}\right) \approx \mathrm{y}_{4}+\mathrm{y}_{5} ; \quad \mathrm{U}\left(\mathrm{X}_{2} \mathrm{X}_{4}: \mathrm{VX}_{4}\right) \approx-\mathrm{y}_{4}+\mathrm{y}_{6} ; \mathrm{U}\left(\mathrm{X}_{3} \mathrm{X}_{4}: \mathrm{VX}_{4}\right) \approx-\mathrm{y}_{5}-\mathrm{y}_{6} \text {. }
$$

Now we are in a position to analyse the system of equations 48 in MAA. Together with the notations introduced above we note that $h_{1}, h_{2}$ and $h_{3}$ functions are of $\mathrm{O}\left(\mathrm{C}_{\mathrm{V}} \mathrm{C}_{4}\right)$. Then for the limit $\mathrm{c}_{4} \rightarrow 0$ we will have only three essential equations for the three unknowns $\mathrm{h}, \mathrm{z}_{1}=\mathrm{y}_{4}+\mathrm{y}_{5}$, and $\mathrm{z}_{2}=\mathrm{y}_{4}-\mathrm{y}_{6}$ :

$$
\mathrm{M}_{0} \mathrm{c}_{\mathrm{v}}\left[\mathrm{z}_{1}\left(\mathrm{w}_{1} \mathrm{f}_{11}+\mathrm{w}_{4} \mathrm{f}_{44}-\mathrm{w}_{3} \mathrm{f}_{13}{ }^{(3)}\right)+\mathrm{z}_{2}\left(\mathrm{w}_{3} \mathrm{f}_{13}{ }^{(3)}-\mathrm{w}_{2} \mathrm{f}_{12}{ }^{(2)}\right)\right]+\mathrm{c}_{1} \mathrm{~h}\left(2 \mathrm{w}_{4}+\mathrm{M}_{0} \mathrm{w}_{1} \mathrm{~F}_{1}\right)=\mathrm{c}_{1} \mathrm{c}_{4} \mathrm{C}_{\mathrm{v}} \text {, }
$$

$$
\begin{array}{r}
\mathrm{M}_{0} \mathrm{c}_{\mathrm{v}}\left[\mathrm{z}_{1}\left(-\mathrm{w}_{3} \mathrm{f}_{33}-\mathrm{w}_{4} \mathrm{f}_{44}+\mathrm{w}_{1} \mathrm{f}_{13}{ }^{(1)}\right)+\mathrm{z}_{2}\left(\mathrm{w}_{3} \mathrm{f}_{33}+\mathrm{w}_{4} \mathrm{f}_{44}-\mathrm{w}_{2} \mathrm{f}_{23}{ }^{(2)}\right)\right]+\mathrm{c}_{3} \mathrm{~h}\left(2 \mathrm{w}_{4}+\mathrm{M}_{0} \mathrm{w}_{3} \mathrm{~F}_{3}\right) \\
=\mathrm{c}_{3} \mathrm{C}_{4} \mathrm{C}_{\mathrm{v}}, \\
\mathrm{M}_{0} \mathrm{c}_{\mathrm{v}}\left[\mathrm{z}_{1}\left(\mathrm{w}_{1} \mathrm{f}_{12}{ }^{(1)}-\mathrm{w}_{3} \mathrm{f}_{23}{ }^{(3)}\right)+\mathrm{z}_{2}\left(-\mathrm{w}_{2} \mathrm{f}_{22}-\mathrm{w}_{4} \mathrm{f}_{44}+\mathrm{w}_{3} \mathrm{f}_{23}{ }^{(3)}\right)\right]+\mathrm{c}_{2} \mathrm{~h}\left(2 \mathrm{w}_{4}+\mathrm{M}_{0} \mathrm{w}_{2} \mathrm{~F}_{2}\right)=\mathrm{c}_{2} \mathrm{c}_{4} \mathrm{C}_{\mathrm{v}},
\end{array}
$$


where $\mathrm{f}_{44}$ is given by Eqn 32, all the $\mathrm{f}_{\mathrm{ij}}(\mathrm{j})$ and $\mathrm{F}_{\mathrm{i}}$ are given by relations Eqns 4, 16, 17 and 18. Therefore, the system of Eqns $10-14$ (for the collective correlation quantitities) needs to be solved first before one can solve the system of equation for the tracer correlation quantities.

It is clear that equations 39, 40 and 41 can be used for all three tracer diffusion coefficients (separately): if $\mathrm{w}_{4}=\mathrm{w}_{1}$, then the solution to the system gives the tracer correlation factor $\mathrm{f}_{1}$ for the $\mathrm{X}_{1}$ tracers; if $\mathrm{w}_{4}=\mathrm{w}_{2}$, then we obtain the tracer correlation factor $f_{2}$ for the $X_{2}$ tracers and if $w_{4}=w_{3}$, then we obtain the tracer correlation factor $\mathrm{f}_{3}$ for the $\mathrm{X}_{3}$ tracers.

Manning's (1971) solution for the tracer correlation effect for the ternary random alloy can be given as follows:

$$
\mathrm{h}^{\mathrm{M}}=\mathrm{C}_{\mathrm{V}} \mathrm{C}_{4}\left(\mathrm{H}+2 \mathrm{w}_{4}\right)^{-1},
$$

where the $\mathrm{H}$ function is a real positive solution to Eqn 31.

The systems Eqns $10-14$ and Eqns $39-41$ for the case when $\mathrm{w}_{1}=\mathrm{w}_{2}=\mathrm{w}_{3}=\mathrm{w}_{4}=1$ have the following trivial solutions:

$$
\begin{gathered}
g_{1}^{0}=-0.5 c_{v} c_{1} c_{2}\left(1-f_{0}\right) ; \quad g_{2}^{0}=-0.5 c_{v} c_{1} c_{3}\left(1-f_{0}\right) ; \quad g_{3}{ }^{0}=-0.5 c_{v} c_{2} c_{3}\left(1-f_{0}\right) ; \\
h^{0}=0.5 c_{v} c_{4}\left(1-f_{0}\right) ; y_{i}^{0}=0, \text { for } i=1, \ldots, 6
\end{gathered}
$$

It is suggested always to use these solutions as a starting point in the usual procedure for the solving a system of nonlinear equations.

\section{§ 3. Monte Carlo Simulation.}

In our Monte Carlo computer simulations we made direct use of the following equations for the collective correlation factors (Allnatt 1982, Allnatt and Allnatt 1984):

$$
\mathrm{f}_{\mathrm{ii}}=<\Delta \mathbf{R}_{\mathbf{i}}{ }^{2}>\left(<\mathrm{N}_{\mathrm{i}}>\mathrm{a}^{2}\right)^{-1}, \quad \mathrm{f}_{\mathrm{ij}}{ }^{(\mathrm{i})}=<\Delta \mathbf{R}_{\mathbf{i}} \Delta \mathbf{R}_{\mathbf{j}}>\left(<\mathrm{N}_{\mathrm{i}}>\mathrm{a}^{2}\right)^{-1},
$$

where $\Delta \mathbf{R}_{\mathbf{i}}$ is the displacement of all atoms of species $\mathrm{i}$ in the system in time $t, \mathrm{~N}_{\mathrm{i}}$ is the total number of jumps of atoms of type $\mathrm{i}$ in time $\mathrm{t}$, and $\mathrm{a}$ is the jump distance. Details of this type of calculation can be found in Allnatt and Allnatt (1984) and Belova and Murch (2000b). General details of Monte Carlo simulations of diffusion kinetics can be found in the review by Murch (1984). The number of observations used in the present calculations was at least 20000 . Determining the number of jumps in each observation turned out not to be without difficulties. In the case of tracer diffusion in the binary random alloy it was found that at least 100 jumps per atom (of the slower species) were required for convergence (Belova and Murch 2000a). Failure to do this in early published Monte Carlo work resulted in the Manning formalism appearing to be (falsely) superior to HE and MAA, as mentioned in section 1 . On the other hand, for collective diffusion in the binary alloy it was found that only several 
hundred atom jumps in toto per observation were required for convergence (Belova and Murch 2000b). In the ternary random alloy, we found that simply using several hundred jumps in each observation, as used in the binary random alloy, does not give converged results, though they do happen to agree quite closely with the Manning formalism. In order to get convergence one needs about 100 jumps per atom in each observation. The collected evidence therefore is that the Manning formalism is generally equivalent to short times in a simulation. In the binary random alloy case short times suffice because Manning, HE and MAA all give the same (very accurate) expressions for the collective correlation factors and convergence is obtained very quickly. This is not the case in the ternary random alloy. As a result far more computational time is required for the ternary system compared with the binary.

To obtain the tracer correlation factors we made use of the well known equation:

$$
\mathrm{f}_{\mathrm{i}}=<\Delta \mathbf{r}_{\mathrm{i}}^{2}>\left(<\mathrm{n}_{\mathrm{i}}>\mathrm{a}^{2}\right)^{-1},
$$

Where $<\mathrm{n}_{\mathrm{i}}>$ is the average number of jumps of the atoms of type $\mathrm{i}$ and $<\mathbf{r}_{\mathbf{i}}{ }^{2}>$ is the mean squared displacement of all the atoms of type i. For further details see Belova and Murch (2000a). We averaged over the equivalent of at least 20000 atoms. As was found for tracer diffusion in the binary system some 100 jumps for the slowest diffuser were required to obtain convergence of the tracer correlation factors.

\section{§ 4. Simulation Results}

For the ternary alloy we present a cross-section of results for the collective correlation factors. In Figs 1,2 we show as data points our Monte Carlo results for the collective correlation factors as functions of $c_{1}$ with $c_{3}=0.1,0.3$ and 0.6 for the exchange frequency ratios $\mathrm{w}_{1} / \mathrm{w}_{2}=10.0$ and $\mathrm{w}_{1} / \mathrm{w}_{3}=0.1$. Corresponding results from Manning (1971) are shown as broken lines and from MAA (as described in this study) as solid lines. It is immediately clear that MAA is consistently in excellent agreement with the Monte Carlo results whereas in general, the results of Manning's formalism are only in semi-quantitative agreement. The off-diagonal collective correlation factors especially are seen often to be in poor agreement with Manning's theory. Further extensive Monte Carlo data at other compositions, not shown here for brevity, are in similar agreement with the self-consistent theory.

In Fig 3 we show as data points corresponding Monte Carlo results for the tracer correlation factors as functions of $c_{1}$ with $c_{3}=0.1,0.3$ and 0.6 for exchange frequency ratios $\mathrm{w}_{1} / \mathrm{w}_{2}=10.0$ and $\mathrm{w}_{1} / \mathrm{w}_{3}=0.1$. Results from Manning (1971) are shown as broken lines and from MAA (as described in this study) as solid lines. Similar to the collective correlation factors presented above, it is immediately clear that MAA is in excellent agreement with the Monte Carlo results whereas the results of Manning's formalism remain only in semi-quantitative agreement. Again, further extensive Monte Carlo data, not shown here for brevity, are in similar agreement with MAA.

Accordingly, it is quite clear that for the ternary random alloy the MAA formalism shows a similar level of agreement with Monte Carlo data as seen earlier for the binary random alloy and that MAA is definitely the formalism of choice for describing diffusion kinetics in those disordered binary and ternary alloy systems that can be reasonably described by the random alloy model. 


\section{$\S 5$. Conclusions}

In this study, collective and tracer diffusion kinetics have been addressed for the ternary random alloy. A formal solution from the MAA self-consistent theory has been derived for collective diffusion and compared with the corresponding solution for the binary random alloy. It was shown that the Manning (1971) result can be found from the MAA theory by neglecting certain terms in the expressions. Tracer diffusion in the ternary alloy was treated from the perspective of a special case of the MAA description of the quaternary random alloy. Results from Monte Carlo calculations for tracer and collective correlation factors (for the bcc ternary random alloy) were found to be in excellent agreement with the MAA theory but in only semiquantitative agreement with the Manning (1971) theory.

Use of the MAA formalism to analyse experimental interdiffusion data is considerably more complicated than use of the Manning (1971) formalism. Use of both of these formalisms to analyse interdiffusion data in the Fe-Ni-Cr system will be published shortly (Belova and Murch, to be published).

\section{Acknowledgments}

We wish to thank the Australian Research Council (Large Grants Scheme) for its support of this research. One of us (IVB) also wishes to thank the Australian Research Council for the award of a Queen Elizabeth II Fellowship.

\section{REFERENCES}

Allnatt, A.R., 1982, J.Phys. C., 15, 5605.

Allnatt, A.R. and Allnatt, E.L., 1984, Phil. Mag. A, 49, 625.

Allnatt, A.R. and Lidiard,A.B., 1993, Atomic Transport in Solids (Cambridge:

Cambridge University Press).

Belova, I.V. and Murch, G.E., 2000a, Phil. Mag. A, 80, 1469; 2000b, Phil.Mag.A.,80, 599; 2000c, Phil.Mag. A, 80, 2365; 2001, Phil. Mag.A, 81,1749.

Holdsworth, P.C. and Elliott, R.J., 1986, Phil. Mag. A, 54, 601.

Le Claire, A.D. 1970, Physical Chemistry-An Advanced Treatise, Vol.10, edited by H. Eyring, D. Henderson and W.Jost (New York: Academic Press).

Manning, J.R., 1968, Diffusion Kinetics for Atoms in Crystals, (Princeton: Van Nostrand-Reinhold); 1971, Phys. Rev. B, 4,1111.

Moleko, L.K. and Allnatt, A.R., 1988, Phil. Mag. A, 58, 677.

Moleko, L.K., Allnatt, A.R. and Allnatt, E.L., 1989, Phil. Mag. A, 59, 141.

Murch, G.E., 1984, Diffusion in Crystalline Solids, edited by G.E.Murch and A.S.Nowick (Orlando, Florida: Academic Press) Chapter 7. p.379.

Murch, G.E. and Qin, Z., 1994, Defect Diffusion Forum, 109,1. 


\section{Figure Captions}

Figure 1. The diagonal collective correlation factors $\mathrm{f}_{11}, \mathrm{f}_{22}$ and $\mathrm{f}_{33}$ as functions of $\mathrm{c}_{1}$ at $\mathrm{w}_{1} / \mathrm{w}_{2}=10.0$ and $\mathrm{w}_{1} / \mathrm{w}_{3}=0.1$. a) $\mathrm{c}_{3}=0.1$; b) $\mathrm{c}_{3}=0.3$ and c) $\mathrm{c}_{3}=0.6$. Data points: Monte Carlo results; solid lines: MAA theory, Eqns 18-20; dashed lines: Manning (1971) theory, Eqns 28-30.

Figure 2. The off-diagonal collective correlation factors $\mathrm{f}_{12}{ }^{(1)}, \mathrm{f}_{13}{ }^{(3)}$ and $\mathrm{f}_{23}{ }^{(2)}$ as functions of $\mathrm{c}_{1}$ at $\mathrm{w}_{1} / \mathrm{w}_{2}=10.0$ and $\mathrm{w}_{1} / \mathrm{w}_{3}=0.1$. a) $\mathrm{c}_{3}=0.1$; b) $\mathrm{c}_{3}=0.3$ and $\mathrm{c}$ ) $\mathrm{c}_{3}=$ 0.6. Data points: Monte Carlo results; solid lines: MAA theory, Eqns 18-20; dashed lines: Manning (1971) theory, Eqns 28-30.

Figure 3. The tracer correlation factors $\mathrm{f}_{1}, \mathrm{f}_{2}$ and $\mathrm{f}_{3}$ as functions of $\mathrm{c}_{1}$ at $\mathrm{w}_{1} / \mathrm{w}_{2}=10.0$ and $\mathrm{w}_{1} / \mathrm{w}_{3}=0.1$. a) $\mathrm{c}_{3}=0.1$; b) $\mathrm{c}_{3}=0.3$ and c) $\mathrm{c}_{3}=0.6$. Data points: Monte Carlo results; solid lines: MAA theory (Eqns 38-40); dashed lines: Manning (1971) theory, Eqns 41,42. 